\title{
Competitiveness of Selected Pasture Plant Species with Parthenium Weed (Parthenium hysterophorus L.)
}

\author{
Ibrahim Mehdi ${ }^{1,}$, , Lisanework Nigatu ${ }^{2}$, Alemayehu Mengistu ${ }^{3}$ \\ ${ }^{1}$ College of Dryland Agriculture, Jigjiga University, Jigjiga, Ethiopia \\ ${ }^{2}$ College of Agriculture and Environmental Sciences, Haramaya University, Dire-Dawa, Ethiopia \\ ${ }^{3}$ Addis Ababa Urael Branch, Addis Ababa, Ethiopia
}

Email address:

mehdi.ibrahim6@gmail.com (I. Mehdi), lisaneworkn@yahoo.com (L. Nigatu), alemayehumengistu@yahoo.com (A. Mengistu) ${ }^{*}$ Corresponding author

\section{To cite this article:}

Ibrahim Mehdi, Lisanework Nigatu, Alemayehu Mengistu. Competitiveness of Selected Pasture Plant Species with Parthenium Weed (Parthenium hysterophorus L.). American Journal of Environmental Protection. Vol. 6, No. 5, 2017, pp. 112-119. doi: 10.11648/j.ajep.20170605.12

Received: August 4, 2017; Accepted: August 18, 2017; Published: September 13, 2017

\begin{abstract}
The study was conducted to come across with competitive test pasture species grown in combination with parthenium at varying levels of density under field in factorial experiment using Randomized Complete Block Design. The treatments consisted of 10,20 and 30 plants of either test species grown together with 30,20 or 10 parthenium other than pure culture of each species with four replications. The species showed a significant degree of difference $(\mathrm{P}<0.05)$ in inhibition efficiency on growth attributes of parthenium. Among the species, C. ciliaris, C. gayana and P. coloratum were strongly competitive (> 50\% IE) while D. intortum and L. purpureus were ranked as moderately competitive $(<50 \%$ IE) with inhibition efficiency of 59, 68 and 73, 36 and $47 \%$ on dry matter biomass at heavier level of density respectively. At medium level of density the species had 39, 52 47, 21 and $25 \%$ and 11, 19 18, 9 and 13\% IE at lower levels of density respectively. Increasing mixing level from the lower to medium density level their IE increased by 27,33 and $29 \%$ while by 20,16 and $26 \%$ when mixing level increased from medium to heavier level of density respectively. Similarly, at heavier density a reduction of 39,44 and $52 \%$ on height, 30,41 and $40 \%$ on number of tillers and/or branches and 24,30 and $36 \%$ on leaf area of parthenium respectively. At this density, the species had RCC of 2.57, 1.69 and 2.33 and AI of $0.61,0.52$ and 0.68 respectively. Besides, a strong association seen concerning IE and growth attributes of species with a correlation coefficient of $r=0.848,0.795,0.549$ and 0.413 between dry matter biomass, height, number of tiller and/or branch and leaf area respectively. Therefore, it can be suggested that successful management of parthenium can be achieved through biological approach using competitive pastures species in rangelands and/or other infested locations that believed to be cost effective, environmentally friendly and its sustainability could play a substantial role.
\end{abstract}

Keywords: Biological Control, Invasive Alien, Pasture, Relative Crowding Coefficient, Species Composition

\section{Introduction}

Poor management of rangelands as extensive grazing along with increasing deforestation for agriculture, fuel wood and recurrent drought results biodiversity reduction and declines the nutritive value of indigenous species and gradual replacement of indigenous species by low palatable and/or unpalatable species [1]. Besides, invasion of undesirable herbaceous and woody plant species have been threatening the pastoral production system in the horn of Africa particularly eastern Ethiopia [2]. Hence, invasive alien species (IAS) are the major challenges for countries like Ethiopia, striving for food security through significant reduction in production potential of rangelands [3]. They are of major concern due to high spreading capability, competitiveness and abilities to colonize new areas within a short period of time. Nowadays, most of the rangelands in the areas are invaded by noxious weed, one of which that aggressively invaded rangelands is Parthenium [4].

Parthenium ( $P$. hysterophorus L.) is annual broadleaf 
invasive weed from the family Asteraceae. Parthenium weed have originated in tropical and/or subtropical America and spread accidentally in many countries like Australia, India, South Africa, Ethiopia, Sri Lanka, Pakistan, Vietnam and China where it become problematic within rangelands and cropping areas [5]. The weed introduced into Ethiopia through provision of humanitarian emergency food aid from the USA in the late 1970s and now has spread to all regions of the country [6]. The weed reduces the yield of crops and pastures and when consumed by animals it taints their milk and meat, reducing their value, parthenium also causes human health problems such as sever contact dermatitis, hay fever and respiratory stress.

Characteristics of weed (viz. rapid seed germination, rapid growth, short or prolonged life span, high viable seed production, persistent soil seed banks and release of allelopathic chemicals) are involved in its high invasive ability. Several approaches have been used to manage the weed but most have a limited effect. Among these, physical methods can be effective but direct skin contact with the weed during hand pulling can be injurious to health and time consuming [7]. The use of herbicides provides faster control but needs to be reapplied on annual basis when the weed reemerges from soil seed bank [8]. Chemical control also considered having a number of negative impacts including its high cost, negative impacts upon human health and repeated use lead to herbicide resistance development. Therefore, integrated weed management approach through competitive pasture species has shown potential in several parts of the world including India [9], Ethiopia, Pakistan and Australia [10]. The present research aims to quantify the effects of selected competitive beneficial pasture plant species as a biological control agent upon parthenium growth attributes under field condition at Dire-Dawa, Ethiopia.

\section{Materials and Methods}

\subsection{Site Description}

The experiment was conducted in Tony farm, one of the experimental sites of Haramaya University, located in DireDawa Administrative Region. The farm is situated in eastern part of Ethiopia between $9^{\circ} 28^{\prime} 1^{\prime \prime} \mathrm{N}$ and $9^{\circ} 49^{\prime} 1^{\prime \prime} \mathrm{N}$ latitude and between $41^{\circ} 38^{\prime} 1^{\prime \prime} \mathrm{E}$ and $42^{\circ} 19^{\prime} 1^{\prime \prime} \mathrm{E}$ longitude. It is bordered by eastern Hararghe administrative zone of Oromia region in southeast and Shinile zone of Somali Region in the North, East and West. It has warm and dry climate with a low level of precipitation with total area of $197,700 \mathrm{~h}$. The annual max and min temperature was 32.4 and $18.2^{\circ} \mathrm{C}$ respectively with the annual average rainfall was $604 \mathrm{~mm}$. The range of altitude of the region is between $960-1760 \mathrm{~m}$ a.s.l.

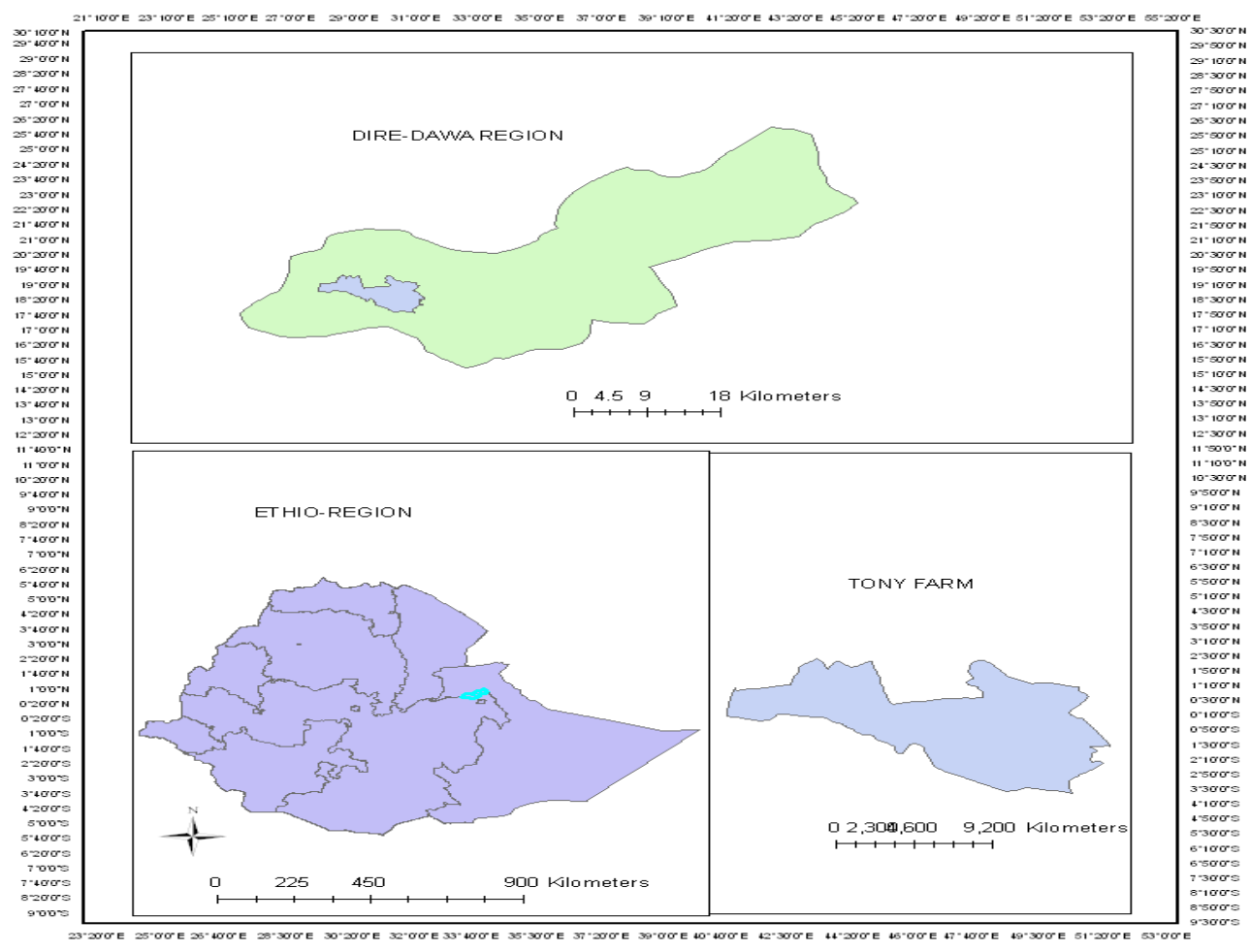

Figure 1. Map of the study area.

\subsection{Sources of Pasture Seeds}

Among the pasture species conducted, the two grasses; $C$. ciliaris and P. coloratum were obtained from Somali Region Pastoral and Agro-Pastoral Research Institute (SoRPARI) and the two legumes; D. intortum and L. purpureus from the 
Ethiopian Institute of Agricultural Research (EIAR). However, a seed of C. gayana was obtained from International Livestock Research Institute (ILRI). On the other hand, the mature seeds of parthenium were collected from plants grown within the experimental site. Upon collection, the seeds of parthenium were hand threshed and air-dried in an open sundry in order to minimize dormancy and to retain seed viability.

\subsection{Germination Trial}

Germination rate of test species and parthenium seeds were carried out in Petri dishes (90mm diameter), lined with double layers of filter papers (3mm Whattman No 1). The seeds were incubated in germination chamber using 50 seeds per Petri dishes except L. purpureus, which filled with 15 seeds due to its larger size. The filter papers adequately moistened with distilled water two times a day. Petri dishes were randomly placed on a table and randomized every day to ensure similar amount of light. After observing seedlings, germinated seedlings were carefully counted for duration of 25 days. During the experiment, average daily max and min temperature was 33 and $20^{\circ} \mathrm{C}$ respectively. Finally, rate of germination was calculated using the formula [11].

$$
\begin{gathered}
G R=N_{1}+1 / 2\left(N_{2}-N_{1}\right)+1 / 3\left(N_{3}-N_{2}\right)+\cdots \\
+1 / n\left(N_{n}-N_{n-1}\right)
\end{gathered}
$$

Where;

$N_{1}, N_{2}, N_{3}, N_{n-1}$ and $N_{n}$ were proportions of germinated seeds observed afterwards in the first, second, third... (n-1) and (n) day.

\subsection{Soil Sampling and Analysis}

The soil samples were collected using soil auger from four corners and centres of each block to maximum depth of $20 \mathrm{~cm}$. Five soil samples were taken from each block and mixed thoroughly to form a composite sample and a sub-samples of $200 \mathrm{~g}$ was taken. Each sub-sample was replicated two times from each respective block. The samples were air dried in a shade for a week, placed in paper bags and then brought to the Central Soil Laboratory of Haramaya University for analysis of physico-chemical properties following the standard procedures sated by [12].

\subsection{Experimental Procedures}

A uniform, well-drained location with a relatively level surface $(8.40 \times 19.60 \mathrm{~m})$ was selected. The area was cultivated using hoe to a depth of $30 \mathrm{~cm}$ and left for a week to give enough time to kill previous plant species there. The site was prepared to be levelled and then divided into four blocks $(3.70 \times 9.30 \mathrm{~m})$. Blocking was done in such a way that they were rectangular and perpendicular to the direction of expected gradient. The blocks was further partitioned and marked out into three columns by seven rows having a total of 21 plots
$(0.90 \times 0.90 \mathrm{~m})$ per block using a measuring tape, string and wooden pegs. The spacing of $1 / 2$ and $1 \mathrm{~m}$ wide pathway was maintained between each plot and block respectively, which used to assist with replication identification and trial activities. The spacing of 10 and $30 \mathrm{~cm}$ was maintained between each plant and planting row respectively. The pasture seeds were sown in each plot with slightly excess of the required proportion at five different levels of test species-to-parthenium. After $10^{\text {th }}$ day of emergence, seedlings were thinned to the required proportions and keep on to grow for four months. All emerged weeds other than parthenium were removed manually from the entire plots.

\subsection{Experimental Treatments}

Treatments were established from a pure stand of one pasture plant and that progressively replaced with plants of the second pasture plant up to the pure stands of the later one. Besides the pure stand of each species at the same density levels, treatments with the proportion of 75:25, 50:50 and 25:75 were frequently used. Total density of plants in each plot was holding constant (40 plants per plot) while the proportion between test species and parthenium were varied. The treatments were replicated four times using pure parthenium plot as a control treatment.

\subsection{Experimental Design}

The treatments were arranged in replacement approach with an addition series experiment [13]. Completely Randomized Design (CRD) and Factorial Randomized Complete Block Design (RCBD) used for germination bioassay and field trial respectively.

\subsection{Data Collections}

Height: The height $(\mathrm{cm})$ of both parthenium and test species were measured from the ground level to the tip of each plant by using measuring tape by taking five plants at random per plot.

Number of tiller and/or branch: Numbers of tillers and/or branches of those randomly selected parthenium and test species were counted.

Leaf area: Six leaves per plant (the upper, middle and lower part) were randomly destructed from those selected species and measured using leaf area scanner (CI-202 Portable Leaf Area Meter).

Dry matter biomass: The remaining plants of parthenium and test species per plot were harvested and placed in labelled paper bags. The fresh weights of the samples were measured and recorded. The samples then brought to Animal Nutrition Laboratory of Haramaya University for dry biomass determination. The samples were oven dried at $72^{\circ} \mathrm{C}$ for 48 hours. The mean values of measured growth attribute used for percentage inhibition efficiency determination using:

$$
I E=\left(\frac{\text { Control }- \text { Treatment }}{\text { Treatment }}\right) \times 100
$$




\subsection{Relative Crowding Coefficient and Agressivity Index}

Competitive ability of each test species and parthenium at different mixing proportions were compared using relative crowding coefficient (RCC) and aggressivity index (AI) on dry matter basis. According to [14], the relative crowding coefficient of the test species-to-parthenium mixture was calculated as:

$$
\begin{aligned}
R C C_{w t} & =\frac{D M B_{w t}\left(N_{t w}\right)}{D M B_{w}-D M B_{w t} N_{w t}} \\
R C C_{t w} & =\frac{D M B_{t w}\left(N_{w t}\right)}{D M B_{t}-D M B_{t w} N_{t w}}
\end{aligned}
$$

Where;

$D M B_{w t}=$ dry matter biomass of parthenium weed mixed with test species

$D M B_{t w}=$ dry matter biomass of test species mixed with parthenium weed

$R C C_{w t}=$ relative crowding coefficient of parthenium weed mixed with test species

$R C C_{t w}=$ relative crowding coefficient of test species mixed with parthenium weed

$N_{w t}=$ sowing proportion of parthenium weed mixed with test species

$N_{t w}=$ sowing proportion of test species mixed with parthenium weed

According to [15], the aggressivity index of the test species-to-parthenium weed was calculated as:

$$
\begin{aligned}
& A I_{t w}=\left(\frac{D M B_{t w}}{D M B_{t} \times N_{t w}}\right)-\left(\frac{D M B_{w t}}{D M B_{w} \times N_{w t}}\right) \\
& A I_{w t}=\left(\frac{D M B_{w t}}{D M B_{w} \times N_{w t}}\right)-\left(\frac{D M B_{t w}}{D M B_{t} \times N_{t w}}\right)
\end{aligned}
$$

Where;

$\mathrm{AI}_{\mathrm{tw}}=$ aggressivity index of test species mixed with prthenium weed

$\mathrm{AI}_{\mathrm{wt}}=$ aggressivity index of parthenium weed mixed with test species

$\mathrm{DMB}_{\mathrm{tw}}=$ dry matter biomass of test species mixed with parthenium weed

$\mathrm{DMB}_{\mathrm{wt}}=$ dry matter biomass of parthenium weed mixed with test species

$\mathrm{N}_{\mathrm{tw}}=$ sowing proportion of test species mixed with parthenium weed

$\mathrm{N}_{\mathrm{wt}}=$ sowing proportion of parthenium weed mixed with test species

\subsection{Statistical Analysis}

The data on germination rate were statistically analysed using one-way ANOVA and Least Significance Difference (LSD) was used to explain treatment means. However, twoway ANOVA [16] for growth attributes of test species and parthenium and Duncan multiple range test (DMR) used for mean difference between treatments mean. Lastly, correlation analysis (CA) was done to determine if there was any association between inhibition efficiency of pasture species and growth attributes. Thus, the statistical model was:

$$
Y_{i y j}=\mu+V_{i}+N_{y}+B_{j}+(V * N)_{i y}+e_{i y j}
$$

Where;

$Y_{i y j}=$ the response variable

$\mu=$ the overall mean

$V_{i}=$ the $\mathrm{i}^{\text {th }}$ effect of pasture species

$N_{y}=$ the $\mathrm{y}^{\text {th }}$ effect of density level (mixing proportion)

$B_{j}=$ the $\mathrm{j}^{\text {th }}$ effect of block

$(V * N)_{i y}=$ interaction effect of species with density level

$e_{i y j}=$ the error component of interaction

\section{Results and Discussion}

\subsection{Germination Rate}

Germination study revealed that there was a significant difference $(\mathrm{P}<0.05)$ in germination of entire species and parthenium. The maximum germination index was recorded for L. purpureus with index of 2.25. The germination index decreased slightly for seeds of $C$. ciliaris, C. gayana, $P$. coloratum and parthenium with germination index of 1.32 , $1.41,1.89$ and 1.41 and the lowest index recorded for $D$. intortum with index of 0.67 . Since the species are different, the seeds of different species had different requirements for light, temperature and moisture during germination. Moreover, factors such as dormancy, seed-coat structure with respect to water uptake, moisture, light and temperature might influence the rate of germination of individual seed were the main reason for the variation in germination.

\subsection{Soil Physico-Chemical Analysis}

The texture of the soil of the study area was sandy clay with other physico-chemical properties (Table 1)

Table 1. Some soil physico-chemical properties of the experimental site.

\begin{tabular}{llllllllll}
\hline Block & $\mathbf{p H}$ & OC(\%) & OM(\%) & TN(\%) & Sand(\%) & Clay(\%) & Silt(\%) & Av.P(ppm) & CEC(meq/100Kg) \\
\hline I & 6.48 & 1.48 & 2.55 & 0.24 & 50.92 & 29.64 & 19.64 & 24.16 & 37.29 \\
II & 6.44 & 1.42 & 4.45 & 0.25 & 54.92 & 26.44 & 18.64 & 14.84 & 32.37 \\
III & 6.42 & 1.46 & 2.52 & 0.25 & 50.92 & 29.44 & 19.64 & 24.14 & 37.98 \\
IV & 6.46 & 1.52 & 2.62 & 0.22 & 51.92 & 26.44 & 21.64 & 14.25 & 33.88 \\
Mean & 6.45 & 1.47 & 2.53 & 0.24 & 52.17 & 27.99 & 19.89 & 19.35 & 35.38 \\
\hline
\end{tabular}

Key; $\mathrm{OC}=$ organic carbon, $\mathrm{OM}=$ organic matter, $\mathrm{TN}=$ total nitrogen, $\mathrm{Av} \cdot \mathrm{P}=$ available phosphorus, $\mathrm{CEC}=$ cation exchange capacity. 


\subsection{Effect of Test Species on Dry Matter Production of Parthenium}

\subsubsection{Species Type}

Dry matter biomass of parthenium mixed with test species were significantly different $(\mathrm{P}<0.05)$ from the dry matter production in pure plot at different levels of planting densities. The finding revealed that at heavier level of density, C. ciliaris, C. gayana, L. purpureus and P. coloratum had 27, 32, 11 and $37 \%$ more inhibition efficiency than the least competitive species, $D$. intortum. Furthermore, the species had well competitive at medium density by $18,31,4$ and $26 \%$ and $2,10,4$ and $9 \%$ at lower density compared to D. intortum respectively.

\subsubsection{Planting Density}

The mean dry matter biomass of parthenium showed that there was a significant reduction $(\mathrm{P}<0.05)$ at different planting densities (Table 2). The pasture species planted at heavier planting density had greater inhibition efficiency compared to medium and lower level of density. Therefore, increasing planting density from 10 to 20 plants the dry matter reduction of parthenium was by $27,33,16,12$ and $29 \%$ with C. ciliaris, C. gayana, D. intortum, L. purpureus and $P$. coloratum respectively. However, increasing planting density from 20 to 30 plants, the reduction of dry matter biomass was by $20,16,15,22$ and $26 \%$ respectively. The important point to note is that the increasing planting density from the lower to medium and to the heavier level of density the inhibition efficiency of species increased. The percent increase in inhibition efficiency was higher when planting density increases from lower level to medium density level. The reason might be that the higher planting density in a community causes a competition for limited resources (light, space, moisture and nutrients); therefore, the more number of plants acquiring the majority of resources as compared to the lesser individuals.

\subsubsection{Species Type and Planting Density}

Under heavier planting density, parthenium dry weight biomass was reduced by greater than $50 \%$ mixed with grasses as compared to its pure plot while below $50 \%$ with legumes. The inhibition efficiency was greater than $40 \%$ at medium planting density with $C$. gayana and $P$. coloratum and less than $30 \%$ with legumes. However, dry matter biomass reduction was less than $20 \%$ at lower levels of density (Table 2). The finding was aligned with [17], who reported that $C$. ciliaris and $C$. gayana were suppressed dry matter biomass of parthenium by 71 and $79 \%$ at Monto while C. ciliaris by $74 \%$ at Injune, respectively in Australia. Another field study by [11] revealed that using C. ciliaris, the growth of parthenium was suppressed by more than $50 \%$. In general, dry matter biomass of parthenium decreased as density of test species increased, which shows that the biomass production of parthenium was inversely related to the density of test species used.

\subsection{Effect of Test Species on Other Growth Attributes of Parthenium}

(Table 2). The mixture of test species had a significant impacts $(\mathrm{P}<0.05)$ on height attainment, number of branches and leaf area of parthenium weed. The height of parthenium was highly inhibited by average reduction of $39,44,27,34$ and $57 \%$ mixed with $C$. ciliaris, $C$. gayana, D. intortum, $L$. purpureus and $P$. coloratum at heavier density level respectively. The result further revealed that the number of branch of parthenium reduced by 46,37 and $15 \%$ at heavier, medium and lower levels of density respectively. Similarly, the mean leaf area of parthenium decreased by 24, 30, 12, 31 and 36 mixed with C. ciliaris, C. gayana, D. intortum, L. purpureus and $P$. coloratum respectively at heavier density levels.

The greater inhibition efficiency of grasses was might be due to rapid seedling establishment, greater plant height, more tillering ability, more leaf area and dry matter accumulation than legumes found to be responsible for their strong suppression (Table 2). The finding was in line with the finding of [18], who reported that growth characteristics of plants such as larger leaf area, greater height and biomass attainment enabled plants to utilize environmental resources more efficiently. Furthermore, [19], reported that native grass species had a good suppressive ability over growth of parthenium despite the fact that their growth characteristics not greater than those of introduced species. It is an interesting to note that native species were generally more suppressive than introduced. The possible explanation might be because of species adaptation ability to a wide range of soil types and climatic condition, which assisted them to be more suppressive. In addition, the species might be inhibit the growth of parthenium weed through release of allelochemicals in agreement with [20].

In the finding, Lablab was in poor inhibition efficiency as it produced the higher dry matter biomass at pure culture while Desmodium was poor in inhibition efficiency and dry matter production. The shorter plant height, lower tillering ability, smaller leaf area and poor biomass accumulation of Desmodium were might be the main factors for poor suppressive ability. The current finding was in line with [21] reported that Cowpea (Vigna unguiculata) a short stature legume was less suppressive over growth of weed than taller plants. Legumes play an important role in mixture with grasses to facilitate suppression of weed by improving the quality and quantity of fodder even if they have low suppressive ability might be the reason.

Another possible reason for their low suppressive ability might be attributable to their poor adaptations to the environment in which they conducted. Moreover, their poor suppressive ability could be due to their susceptibility to allelopatic compounds released from roots and leaves of weed that resulted in retardation of the activities of nitrogen fixing bacteria which in line with [22], noted that a wide range of plant species affected by allelopathic inhibition of 
parthenium. Similarly, [23] reported that Faba bean (Vicia faba L.) had a higher nitrogen fixating ability in absence than presence of weed.

\subsection{Relative Crowding Coefficients and Aggressivity Index}

The relative crowding coefficient of grasses had higher value than parthenium at heavier and medium level of density but legumes had higher value only at heavier density level indicating that the species were more dominant. Parthenium found to be more dominant than legumes at medium and lower level of density and only at lower level of density with grasses. Aggresivity index of the entire species had positive at heavier level of density while the three grasses at medium level of density indicating that the dry matter biomass of parthenium was inhibited in presence of species. The result further showed that the legumes at medium density level and entire test species at lower levels of density had negative value indicating that they were inhibited by parthenium (Table 3). The finding was in contrary to the finding of [24], reported that $C$. ciliaris was dominant at three density levels, $P$. coloratum at two (50:50 and 75:25) whereas $C$. gayana out-competed only at (75:25) level of density in greenhouse. The reason might be due to variations in the greenhouse environment (constant soil moisture and nutrient availability, absence of pests and containment within pots) and field condition, they unable to exert their suppressive potential.

Table 2. Production potential of Parthenium growth attributes grown with pasture plant species with different combination levels.

\begin{tabular}{|c|c|c|c|c|c|}
\hline \multirow[b]{2}{*}{ Species mixture } & \multirow[b]{2}{*}{ Density (\%) } & \multicolumn{2}{|c|}{ Growth attributes } & \multirow[b]{2}{*}{ Leaf Area $\left(\mathrm{cm}^{2}\right)$} & \multirow[b]{2}{*}{ DMB (g/plant) } \\
\hline & & Height (cm) & Tiller/Branch (no.) & & \\
\hline \multirow[t]{4}{*}{ C. ciliaris: P. hysterophorus } & $25: 75$ & $126.57 \pm 4.1^{\mathrm{b}}$ & $6.68 \pm 0.3^{\mathrm{a}}$ & $30.93 \pm 0.9^{\mathrm{a}}$ & $74.7 \pm 0.09^{\mathrm{bc}}$ \\
\hline & $50: 50$ & $89.67 \pm 2.1^{\mathrm{c}}$ & $5.94 \pm 0.4^{b}$ & $25.93 \pm 1.6^{\mathrm{b}}$ & $99.4 \pm 0.39^{\mathrm{de}}$ \\
\hline & $75: 25$ & $82.47 \pm 3.5^{\mathrm{cd}}$ & $5.15 \pm 0.5^{\mathrm{bc}}$ & $24.78 \pm 0.9^{\mathrm{bc}}$ & $110.7 \pm 0.49^{\text {ef }}$ \\
\hline & 100:0 & $82.06 \pm 3.5^{\mathrm{b}}$ & $3.45 \pm 0.4^{\mathrm{b}}$ & $17.95 \pm 0.9^{b}$ & $255.92 \pm 6.24^{\mathrm{b}}$ \\
\hline \multirow[t]{3}{*}{ C. gayana: P. hysterophorus } & $25: 75$ & $115.38 \pm 7.9^{\mathrm{ab}}$ & $6.39 \pm 0.4^{\mathrm{ab}}$ & $30.62 \pm 1.2^{\mathrm{a}}$ & $71.8 \pm 0.32^{\mathrm{bc}}$ \\
\hline & $50: 50$ & $84.95 \pm 3.5^{\mathrm{c}}$ & $5.53 \pm 0.24^{b}$ & $27.76 \pm 1.2^{\mathrm{ab}}$ & $89.3 \pm 0.46^{\mathrm{e}}$ \\
\hline & $100: 0$ & $88.49 \pm 2.2^{\mathrm{ab}}$ & $3.75 \pm 0.3^{\mathrm{ab}}$ & $17.33 \pm 1.2^{\mathrm{b}}$ & $349.07 \pm 9.86^{\mathrm{ab}}$ \\
\hline \multirow[t]{4}{*}{ D. intortum: P. hysterophorus } & $25: 75$ & $122.96 \pm 3.5^{\mathrm{ab}}$ & $6.65 \pm 0.24^{\mathrm{a}}$ & $30.28 \pm 0.9^{\mathrm{a}}$ & $83.1 \pm 0.12^{\mathrm{ab}}$ \\
\hline & $50: 50$ & $107.82 \pm 2.2^{\mathrm{bc}}$ & $6.50 \pm 0.3^{\mathrm{a}}$ & $28.25 \pm 0.9^{\mathrm{ab}}$ & $146.2 \pm 0.22^{\mathrm{bc}}$ \\
\hline & $75: 25$ & $98.96 \pm 2.9^{b}$ & $6.18 \pm 0.3^{\mathrm{ab}}$ & $27.75 \pm 0.9^{\mathrm{ab}}$ & $176.4 \pm 0.43^{\mathrm{d}}$ \\
\hline & $100: 0$ & $37.6 \pm 2.9^{d}$ & $1.9 \pm 0.3^{\mathrm{c}}$ & $11.15 \pm 0.9^{\mathrm{bc}}$ & $238.59 \pm 3.29^{\mathrm{bc}}$ \\
\hline \multirow[t]{3}{*}{ L. purpureus: P. hysterophorus } & $25: 75$ & $118.59 \pm 2.2^{\mathrm{ab}}$ & $6.77 \pm 0.3^{\mathrm{a}}$ & $28.76 \pm 1.2^{\mathrm{ab}}$ & $80.4 \pm 0.08^{b}$ \\
\hline & $50: 50$ & $97.52 \pm 2.9^{\mathrm{bc}}$ & $6.35 \pm 0.3^{\mathrm{ab}}$ & $27.83 \pm 1.2^{\mathrm{ab}}$ & $138.9 \pm 0.13^{\mathrm{c}}$ \\
\hline & 100:0 & $73.42 \pm 2.1^{\mathrm{bc}}$ & $4.00 \pm 0.4^{\mathrm{ab}}$ & $23.93 \pm 1.2^{\mathrm{ab}}$ & $341.89 \pm 5.19^{\mathrm{ab}}$ \\
\hline \multirow[t]{4}{*}{ P. coloratum: P. hysterophorus } & $25: 75$ & $107.64 \pm 2.9^{\mathrm{bc}}$ & $6.67 \pm 0.3^{\mathrm{a}}$ & $29.82 \pm 1.1^{\mathrm{a}}$ & $75.2 \pm 0.84^{\mathrm{bc}}$ \\
\hline & $50: 50$ & $87.75 \pm 2.1^{\mathrm{c}}$ & $4.63 \pm 0.4^{\mathrm{bc}}$ & $25.35 \pm 1.1^{\mathrm{b}}$ & $98.1 \pm 0.16^{\mathrm{de}}$ \\
\hline & $75: 25$ & $67.46 \pm 4.1^{\mathrm{de}}$ & $4.41 \pm 0.3^{c}$ & $21.43 \pm 1.1^{\mathrm{c}}$ & $68.7 \pm 1.65^{\mathrm{g}}$ \\
\hline & $100: 0$ & $87.18 \pm 4.1^{\mathrm{ab}}$ & $3.50 \pm 0.3^{\mathrm{b}}$ & $18.07 \pm 1.1^{\mathrm{b}}$ & $337.41 \pm 6.59^{\mathrm{ab}}$ \\
\hline P. hysterophorus & & $135.14 \pm 7.9^{\mathrm{a}}$ & $7.35 \pm 0.4^{\mathrm{a}}$ & $31.55 \pm 0.9^{\mathrm{a}}$ & $367.4 \pm 0.27^{\mathrm{a}}$ \\
\hline
\end{tabular}

Table 3. The value of Aggressivity Index and Relative Crowding Coefficient of pasture plant species and Parthenium.

\begin{tabular}{|c|c|c|c|c|c|}
\hline Species mixture & Density (\%) & AIt & AIp & $\mathbf{R C C t}$ & RCCp \\
\hline \multirow[t]{3}{*}{ C. ciliaris: P. hysterophorus } & $25: 75$ & -0.41 & 0.41 & 0.10 & 1.37 \\
\hline & $50: 50$ & 0.08 & -0.08 & 0.20 & 0.15 \\
\hline & $75: 25$ & 0.61 & -0.61 & 2.57 & 0.10 \\
\hline \multirow[t]{3}{*}{ C. gayana: P. hysterophorus } & $25: 75$ & -0.48 & 0.48 & 0.09 & 1.61 \\
\hline & $50: 50$ & 0.25 & -0.25 & 0.22 & 0.14 \\
\hline & $75: 25$ & 0.52 & -0.52 & 1.69 & 0.09 \\
\hline \multirow[t]{3}{*}{ D. intortum: P. hysterophorus } & $25: 75$ & -0.71 & 0.71 & 0.07 & 2.55 \\
\hline & $50: 50$ & -0.19 & 0.19 & 0.15 & 0.26 \\
\hline & $75: 25$ & 0.04 & -0.04 & 0.92 & 0.19 \\
\hline \multirow[t]{3}{*}{ L. purpureus: P. hysterophorus } & $25: 75$ & -0.63 & 0.63 & 0.08 & 2.01 \\
\hline & $50: 50$ & -0.32 & 0.32 & 0.16 & 0.24 \\
\hline & $75: 25$ & 0.05 & -0.05 & 0.81 & 0.16 \\
\hline \multirow[t]{2}{*}{ P. coloratum: P. hysterophorus } & $25: 75$ & -0.44 & 0.44 & 0.12 & 1.78 \\
\hline & $50: 50$ & 0.11 & -0.11 & 0.19 & 0.16 \\
\hline
\end{tabular}

\subsection{Production Performance of Pasture Species}

Production performance of test species tested and parthenium were significantly different $(\mathrm{P}<0.05)$ when grown under weed-free plots. Among the species, C. ciliaris, $L$. purpereus and $P$. coloratum were produced higher dry matter biomass while $C$. gayana had the highest dry matter producer and $D$. intortum had to be the lowest as compared to 
others (Table 2). The greater fodder production of test species indicated that they might be more adaptation abilities of soil and climatic condition of the field. Another possible reason might be due to growth behavior of species possessed such as rapid seedling establishment, greater plant height, tillering abilities, leaf area and rapid biomass accumulation. These characteristics were aid them to grow more rapidly and developed a dense plant canopy that consequently shades the weed, deprives its light and most likely soil water and nutrients. The finding was in line with the findings of [25] who stated that parthenium is sensitive to shading from other plant species. Therefore, species with more dry matter production and inhibition efficiency had more competitive that confirmed less parthenium dry matter biomass.

\subsection{Correlation of Growth Attributes and Inhibition Efficiency}

The correlation analysis indicated that good predictors of species suppressive ability upon parthenium were dry matter biomass accumulation, height attainment and number of tiller and/or branch with correlation coefficient of $\mathrm{r}=0.848,0.795$ and 0.549 . The result was in line with findings of [26] who confirmed that rapid attainment of shoot biomass and plant heights were good predictors of suppressive ability. Furthermore, [27] reported that the greater tillering and/or branching ability of plant enhanced plant's ability for light interception and other resources uptake. Similarly, a correlation of leaf area and inhibition efficiency $(r=0.413)$ indicated that early leaf expansion and formation of dense canopy could increase suppressive ability against the growth of parthenium. Thus, selection is better through the assessments of dry matter accumulation, plant height and production of tiller and/or branch numbers.

\section{Summary}

Among the species, the grasses were ranked as a strongly suppressive through rapid biomass accumulation, higher plant height, more tillering and/branching ability and leaf area production. The pasture species having attributes of rapid establishment, faster growth, high biomass production and canopy development played a major role in competitiveness as a result they able to shade and suppress weed growth. Moreover, indigenous grasses had a good tillering ability, rapid growth pattern, producing an extensive root system and leaf canopy quite early after emergence might be due to better adaptation of environmental conditions. The agressivity index and relative crowding coefficient achieved in study would help further to determine suppression of parthenium growth where weed infestation to be found. The result indicated that parthenium found to be a weak competitor as evidenced by the fact that it failed to establish in an areas where there was a dominant pasture plants having close and compact canopy. The study confirmed that species looked-for competitive management are those that able to suppress weed growth and able to produce relatively a higher dry matter biomass for fodder purposes at different climatic conditions through adapting a range of soil types can be used as tool for weed management to minimize the losses to restrain its spread.

\section{Conclusion}

The finding revealed that number of beneficial pasture plant species can suppress growth of parthenium and able to produce sufficient amount of fodder for livestock diet requirement. The study showed that native species in presence of tall, relatively branched biotype with more leaf area and biomass producing type are endowed with a potential capacity to compete with parthenium. Another feature noticed was that under normal circumstances as long as the pastures are not severely overgrazed parthenium cannot causes serious damage but once relatively a large gap occurred in rangeland, the weed emerged as a dominant and its impact may severe. The differences in inhibition efficiency might be due to the differences in growth characteristics of species, rapid and/or slow seedling emergence, rapid growth, adaptation to environmental condition and difference in extracting efficiency of soil water and nutrients through larger root system. Similarly, delay of emergence might be due to the need for after-ripening to lower dormancy or sufficient moisture to start germination.

\section{References}

[1] Alemayehu M., 2004. Rangeland: Biodiversity Concepts, Approaches and the way forward. Addis Ababa University, Faculty of Science, Addis Ababa, Ethiopia. 80p.

[2] Amaha K., 2003. Pastoralism and the need for the future intervention in pastoral areas of Ethiopia. Annual Review on National Dry Land Agriculture Research System, Addis Ababa, Ethiopia.

[3] SERP (South Eastern Rangelands Development Project), 1995. Parthenium hysterophorus and other weeds in Eastern Hararghe, Ethiopia. SERP Technical report (Draft). 81p.

[4] Tamado T. and P. Milberg, 2000. Weed flora in arable fields of Eastern Ethiopia with emphasis on the occurrence of Parthenium hysterophorus L. J. Weed research, 40:507-521.

[5] Dhileepan, K., 2009. Managing Parthenium Weed across Diverse Landscapes: Prospects and Limitations in the Management of Invasive Weeds, (ed. Inderjit). Springer Netherlands 5: 227-259.

[6] Tamado T., L. Ohlander and P. Milberg, 2002. Interference by the weed Parthenium hysterophorus L with grain sorghum: influence of weed density and duration of competition. International Journal of Pest Management, 48: 183-188.

[7] Anonymous, 2009. Parthenium (Parthenium hysterophorus L.), the State of Queensland, Department of Employment, Economic Development and Innovation, Brisbane.

[8] Tamado, T. and P. Milberg, 2004. Control of parthenium (P. hysterophorus L) in grain sorghum (Sorghum bicolor L.) in the smallholder farming system in eastern Ethiopia. Weed Technology 18: 100-105. 
[9] Joshi, S., 1991. Biological 'control of Parthenium hysterophorus L. (Asteraceae) by Cassia uniflora Mill (Leguminosae), in Bangalore, India. Tropical Pest Management 37, 182-184.

[10] O'Donnell, C. and S. W. Adkins, 2005. Management of parthenium weed through competitive displacement with beneficial plants. Weed Biology and Management 5: 77-79.

[11] Wardle, D. A., Ahmed, M., K. S. Nichlson, 1991: Allelopathic influence of nodding thistle (Carduus mutans L.) seeds on germination and radicle growth of pasture plants. J. Agric. Res. 34, 185-191.

[12] Sahlemedhin S. and Taye B, 2000. Procedures for Soil and Plant Analysis. National Soil Research center, Ethiopian Agricultural Research organization.

[13] Rejmanek, M., Robinson, G. R. and E. Rejmankova, 1989. Weed-crop competition: experimental designs and models for data analysis. Weed Science 37: 276-284.

[14] Dewit, C. T., 1960. On competition. Verslagen and Landboukundige Onderzoekingen. The Netherlands. 66:pp 183.

[15] McGilchrist, C. A. and B. R. Trenbath, 1971. A revised analysis of plant competition experiments. Biometrics, 27:659-679.

[16] SAS (Statistical Analysis System Insitute), 2000. SAS/STAT Users' Guide: Statistics Version 8, Statistical Analysis System Insitute. Inc., NC. North Carolina, USA.

[17] Khan N., C. O'Donnell, S. Asad and S. W. Adkins, 2011 Competitive displacement of parthenium weed with beneficial native and introduced pasture plants. Tropical and Subtropical Weeds Research Unit, $7^{\text {th }}$ Australasian Weeds Conference, University of Queensland, Brisbane, Australia.

[18] Aertes, R., Boot, R. G. A. and P. J. M. Vander Aart, 1991. The relation between above and below ground biomass, allocation pattern, and competitive ability. Oecologia 87: pp 551-559.
[19] Bowen, D., Ji, J. and S. W. Adkins, 2007. Management of parthenium through competitive displacement with beneficial plants: a field study, Brisbane. A Report to Queensland Murray Darling Committee. University of Queensland, Brisbane, Australia, p.16.

[20] Knox, J., Jaggi, D. and M. S. Pau, 2010. Evaluation of allelopathic potential of selected plant species on Parthenium hysterophorus L. Egyptian Journal of Biology 12: 57-64.

[21] Wang, G., McGiffen, M. E. and J. D. Ehlers, 2006. Competition and growth of six cowpea (Vigna unguiculata) genotypes, sunflower (Helianthus annuus), and common purslane (Portulaca oleracea). Weed Science 54: 954-160.

[22] Timsina, B., 2007. Impact of Parthenium hysterophorus L. invasion on soil and plant species composition of grasslands of central Nepal. The MSc Thesis, Central Department of Botany, Tribhuvan University, Kathmandu, Nepal.

[23] Strydhorst, S. M., King, J. R., Lopetinsky, K. J. and K. N. Harker, 2008. Weed Interference, Pulse Species and Plant Density Effects on Rotational Benefits. Weed Science 56: 249258.

[24] Shashie, A., 2007. The Impact of Parthenium (Parthenium hysterophorus L.) on the Range Ecosystem Dynamics of the Jijiga Rangeland, Ethiopia. The Msc thesis presented to the school of Graduate studies of Haramaya University, Ethiopia.

[25] Tamado, T., L. Ohlander, and P. Milberg, 2002. Interference by the weed Parthenium hysterophorus L. with grain sorghum: Influence of weed density and duration of competition. International Journal of Pest Manage 48: 183188.

[26] Davies, D. K. H., Hoad, S. P., Maskell, P. R. and K. Topp, 2004. Looking at cereal varieties to help reduce weed control inputs. In Proceedings Crop Protection Northern Britain, Penicuik, p.159-163.

[27] Pimentel, D., 1990. Handbook of Pest Management in Agriculture. CRC Press, Boca Raton, Florida. 